2015 Global Fashion Management Conference at Florence Proceedings: 348-353 (June 2015) http://dx.doi.org/10.15444/GFMC2015.03.03.05 ISSN: 2288-825X

\title{
BRAND PERSONALITY ALIGNMENT AND CONSUMER ENGAGEMENT TO DEFINE COMPETITIVE POSITIONING IN ONLINE FASHION COMMUNITIES: AN INTERDISCIPLINARY METHODOLOGY
}

\author{
Monica Faraoni, University of Florence, Italy ${ }^{1)}$ \\ Belinda Crawford Camiciottoli, University of Pisa, Italy \\ Silvia Ranfagni, University of Florence, Italy
}

\begin{abstract}
New communication challenges for companies that use social media are: 1) the knowledge and control of the degree of alignment between communicated and perceived brand personality in order to measure the effectiveness of competitive positioning, and 2) the measurement of engagement among consumers who share comments about brands in online communities. Our research proposes research tools that can help fashion companies meet these challenges. In particular, we present an innovative methodological approach that combines netnography and text-mining to extract and analyze data from online communities of fashion brands.
\end{abstract}

Keywords: brand personality, consumer engagement, online communities, netnography, text mining, fashion brands

\section{INTRODUCTION}

Social media and online communities increasingly represent an important sphere of interest for marketing managers. They have become a vital tool for companies to transfer brand identity and for consumers to express their perceptions of brand image. Online communications can also shed light on brand personality and thus contribute to defining competitive positioning and fostering the differentiating power of brands (Park \& Roedder John, 2010). Brand personality (hereinafter BP) is defined as a "set of human characteristics associated with a brand" (Aaker, 1997); it combines physical and functional brand attributes with inner features of brand as an expression of human personality traits (Plummer, 2000). The relationship between the consumer and brand personality is anthropomorphic and interpenetrating: consumers recognize themselves in the brand-persona (Ambroise \& Vallette Florence, 2010) or, vice versa, they see the brand-persona as a mirror of themselves. The more consumers recognize themselves in brand personality, the greater the emotional relationship with the brand and the higher the degree of brand attachment (Malär, Krohmer, Hoyer \& Nyffenegger, 2011). Aaker (1997) identifies sincerity, excitement, competence, sophistication, and ruggedness as the five major interactive dimensions of brand personality. Each of these can be further articulated into different facets which companies and consumers use to define and express perceptions of $\mathrm{BP}$, respectively. When comparing company-defined and

\footnotetext{
1) monica.faraoni@unifi.it
} 
consumer-perceived brand personality, two different situations can emerge. Firstly, the brand personality that is communicated may have varying degrees of correspondence with what is actually perceived. This means that discrepancies may exist in terms of brand competitive positioning (i.e., brand personality is not perceived as the company desires) or in terms of how brand personality is communicated (Malär, Krohmer, Hoyer \& Nyffenegger, 2011; Crawford Camiciottoli, Guercini \& Ranfagni, 2014). Therefore, companies need to know and monitor the degree of alignment between communicated and perceived brand personality in order to measure the effectiveness of competitive positioning. Secondly, company communications can produce certain reactions in consumers who share comments about brands in online communities. It is important to be able to evaluate these reactions that serve to indicate the level of consumer engagement (hereinafter CE), defined as "the level of a customer's cognitive, emotional and behavioral investment in specific brand interactions" (Hollebeek, 2011). CE is the expression of the extent to which brand positioning produces an effect of involvement among consumers.

\section{Research objectives}

We investigate online communities in order to develop an interdisciplinary methodology that (a) identifies brand positioning by using brand personality attributes, (b) measures the degree of alignment between communicated and perceived brand personality (brand positioning effectiveness), and (c) determines the level of consumer engagement with a brand personality (brand positioning involvement). The methodological approach we propose combines netnography (Kozinets, 2002) and text-mining (Witten, 2005). Netnography is seen as the digital transposition of traditional ethnography. It is a qualitative technique that involves the collection and content analysis of information collected from online consumer communities. On the contrary, text mining is a quantitative technique that extracts metalinguistic information enables systematic and exhaustive computer-assisted analysis of concepts and structures in texts which would otherwise escape human analytical skills. While these techniques have been used separately to investigate consumer behavior, the integrated approach we propose can be used to analyze brand competitive positioning through the empirical measurement of the degree of alignment between communicated and perceived BP, and the related level of $\mathrm{CE}$. The emerging results allow marketing managers to evaluate brand competitive power, and can thus orient companies in the redefinition of brand personality (effective or perceived) through (re)branding policies. Our analysis is based on a sample of fashion companies which are actively present in online conversations and in social media.

\section{Methodology}

The methodology was articulated into the following phases: (a) selection of the sample of companies in the fashion apparel sector to be analyzed, (b) collection of textual data from online sources, and (c) extraction on linguistic elements as the expression of BP.

The sample: We referred to the database fashionbi.com which classifies a total of 3500 fashion brands the apparel market according to five groups: luxury, premium, diffusion, bridge and mass market. Our analysis will focus on 28 brands classified as premium apparel for two reasons: (a) they include all the "trend setter brands", i.e., brands that 
steer seasonal trends, and (b) they constitute a significant number of brands in the fashionbi.com database and thus presumably also in the sector.

Data collection: To compare company-communicated and consumer-perceived BP, we collected textual data from two different sources:

1) Style.com, a top-ranking blog that is intensely used by fashion bloggers to exchange opinions, comments and perceptions of fashion brands. All the blog posts and comments related to the brands in the sample were downloaded into text files and collected into the blog dataset. Blogs represent a form of spontaneous social interaction that can be observed by researchers in a non-intrusive way in order to understand consumers' attitudes and perceptions about brands (cf. Kozinets, 2002).

2) The websites and/or Facebook pages that contain descriptions of the product and the BP of the brands in the sample. The texts collected into files that made up the second dataset, i.e., the company dataset.

In this way, we were able to collect two parallel datasets containing texts relating to brand personality produced by both companies and consumers.

Data extraction: The text files of both datasets (blog and company) were submitted to a series of analytical procedures to extract adjectives that were expressions of brand personality following the dimensions indicated by Aaker (1997). According to Martin and White (2005), adjectives are the canonical linguistic form for encoding attitudes and emotions that are derived from our experiences and perceptions of our surroundings. Thus, the perception of BP can emerge from the adjectives used by bloggers during online interactions to exchange opinions about brands, but also from the adjectives that companies use in texts on web sources to describe their products.

The techniques used to analyze the adjectives originate in the field of linguistics or, more specifically, corpus linguistics, which analyzes features of texts by means of software programs that can elaborate textual datasets of large dimensions. In this way, it is possible to identify trends and linguistic patterning that cannot be detected with only qualitative content analysis that requires in-depth reading of individual texts. This analytical process was articulated into the following phases:

- grammatical tagging: the company dataset was first run through the software CLAWS4 (Constituent Likelihood Automatic Word Tagging System) that automatically attributes a tag to each word that identifies its part-of-speech: VV $=$ verb, $\mathrm{AT}=$ article, $\mathrm{JJ}=$ adjective, etc.

- identification of adjectives encoding BP: All words that had been tagged as adjectives (JJ) in the company dataset were extracted with the software program WordSmith Tools (Scott, 2010) and then filtered to select only those adjectives that express dimensions of brand personality linked to attitudes and emotions (cf. Aaker, 1997), while eliminating adjectives that express generic attributes such as color, size, and nationality of data that were not of interest. The emerging BP adjectives were then searched for in the corresponding blog dataset using the software AntConc (Anthony, 2011) to determine which ones had also been used by consumers. 
This methodology allowed us to determine which adjectives had been used by the companies to define their own BP, but also by consumers to express their perception of $\mathrm{BP}$, and were thus overlapping between the two.

Data analysis: The adjectives used to express BP identified according to the procedure described above were further analyzed according to two indicators.

1) Brand personality alignment (BPA). This indicator measures the degree of alignment in BP adjectives as defined by companies and as perceived by consumers. For each brand, the number of overlapping adjectives was counted and then normalized as the number of occurrences per 1000 words in each blog file in order to remove the effect of variance generated by different their words counts. The resulting ratios reflect the degree of BP alignment. The higher the value of the BPA indicator, the greater the degree of alignment.

2) Consumer engagement (CE). As indicated above, each file in the blog dataset contains a certain number of words found in the posts/comments inserted by the fashion bloggers as consumers. The ratio between the number of words in the blog file and the number of posts/comments measures the average number of words used by the bloggers each time they insert a post or comment about a particular brand. We can therefore presume that the higher the value of the $\mathrm{CE}$ indicator, the greater the degree of engagement of the blogger/consumer with the brand.

\section{Main results}

The development of a new methodology to measure the positioning of brands in online communities was the first goal of our work. The identification and analysis of BP adjectives allowed us to understand the identity of brands on the market. There was a considerable difference in the BP descriptions of the companies of our sample. In some cases, it is deeply articulated and represented by over 200 different adjectives, while in others only about 20 adjectives are used. In particular, in considering a single brand, brand positioning analysis based on the identification and interpretation of the BP adjectives enabled us to aggregate them in order to build a general concept of identity that firms may transfer to the market. In one case, for instance we identified some combinations of adjectives such as: "accurate, meticulous, intricate", "aesthetic, beautiful", "chic, luxurious", "modern, new, innovative, exciting, contemporary", "distinctive, exclusive, unique", and "feminine, sexy". These combinations describe a brand in which accuracy, aesthetics, modernity, exclusivity and sensual femininity are the core elements of its personality.

The second goal of our research was the determination of the BPA ratio that measures the degree of alignment between communicated and perceived brand personality. In several cases, we observed a high value of the BPA ratio. A higher BPA value means that the adjectives used by consumers when describing the brand overlap to a greater extent with those used by company itself on its corporate website. This has important implications on the effectiveness of brand positioning and communication strategies.

Finally, in relation to $\mathrm{CE}$, we noticed a high variability in the average number of words used by consumers in blogs. The number of words increases when consumers insert 
several comments about the brand after the original post. In fact, the presence of comments to posts implies a broader CE; consumers who comment on the original posts generally provide more articulated opinions as expression of their involvement with the brand.

We represent a matrix (fig. 1) that combines BPA and CE data to illustrate four different situations. In the quadrant 1 , we position all the brands with low BPA and high CE. In such cases, a poor degree of alignment between communicated and perceived BP is accompanied by a high consumer engagement value. This means that the language used by companies to communicate BP produces consumer interest, curiosity and desire to engage in dialogue, even if the BP is not perceived in the desired way. In other words, these companies are able to engage consumers, but not to transmit the BP. This is a risky situation because company communications produce a sort of casual involvement based on divergent perceptions. In quadrant 4, on the contrary, we have an effective communication (high BPA) and a low CE. Here the company is able to convey its BP, but the language used does not arouse interest or passion among consumers. The best situation is found in quadrant 2 in which both BPA and CE ratios have a high value. Companies ranked in this quadrant know how to successfully communicate their own BP and also generate consumer involvement. Finally, quadrant 3 shows a situation in which communication produces neither a corresponding decoding of the desired BP, nor a high level of CE.

In conclusion, the methodology to measure and interpret alignment in BP that we propose can be a strong managerial tool to better understand brand positioning and to define an effective communication strategy that is capable of transferring identity and stimulating engagement with consumers in online communities.

\section{References}

Aaker, J. L. (1997). Dimensions of brand personality, Journal of Marketing Research, 34, 347-356. URL: http://www.jstor.org/stable/3151897

Ambroise, L. \& Vallette-Florence, P., 2010 Métaphore de la personnalité de la marque et stabilité inter-produits d'un baromètre spécifique, Recherche et Applications en Marketing, 25(2), 3-29. URL: http://www.jstor.org/stable/41432262

Anthony, L. (2011). AntConc (Version3.2.4) [Computer Software] Tokyo, Japan. Waseda University Available from http://www.antlab.sci.waseda.ac.jp/

Crawford Camiciottoli, B., Guercini, S., \& Ranfagni, S. (2014). Exploring brand associations: an innovative methodological approach, European Journal of Marketing, 48(4), 30-31. http://dx.doi.org/10.1108/EJM-12-2011-0770

Hollebeek, L. (2011). Exploring customer brand engagement: definition and themes, Journal of Strategic Marketing, 19, 555-573. doi: 10.1080/0965254X.2011.599493

Kozinets, R.V. (2002). The field behind the screen: using netnography for marketing research in online communities, Journal of Marketing Research, 39, 61-72. doi: http://dx.doi.org/10.1509/jmkr.39.1.61.18935

Malär, L., Krohmer, H., Hoyer, D.W., \& Nyffenegger, B. (2011). Emotional brand attachment and brand personality: the relative importance of the actual and the ideal self, Journal of Marketing, 75(7), 35-52. doi: http://dx.doi.org/10.1509/jmkg.75.4.35 
Martin, J. R. \& White, P. R. R. (2005). The language of evaluation. Appraisal in english, Houndmills, Basingstoke, Hampshire, UK: Palgrave MacMillan.

Park, J. K., \& Roedder John, D. (2010). Got to get you into my life: do brand personalities rub off on consumers?, Journal of Consumer Research, 37, 655-669. doi: $10.1086 / 655807$

Plummer, J. T. (2000). How personality makes a difference, Journal of Advertising Research, 40(6), 79-83. URL: journals.cambridge.org/article_S002184990000012X

Scott, M. (2010). Wordsmith Tools Version 5.0, Oxford University Press, Oxford.

Witten, I. H. (2005). Text mining. In M.P. Singh (Ed.), Practical Handbook of Internet Computing, (pp. 14.1-14.22) Boca Raton, Florida: Chapman \& Hall/CRC Press.

Figure 1. Alignment/Engagement Matrix

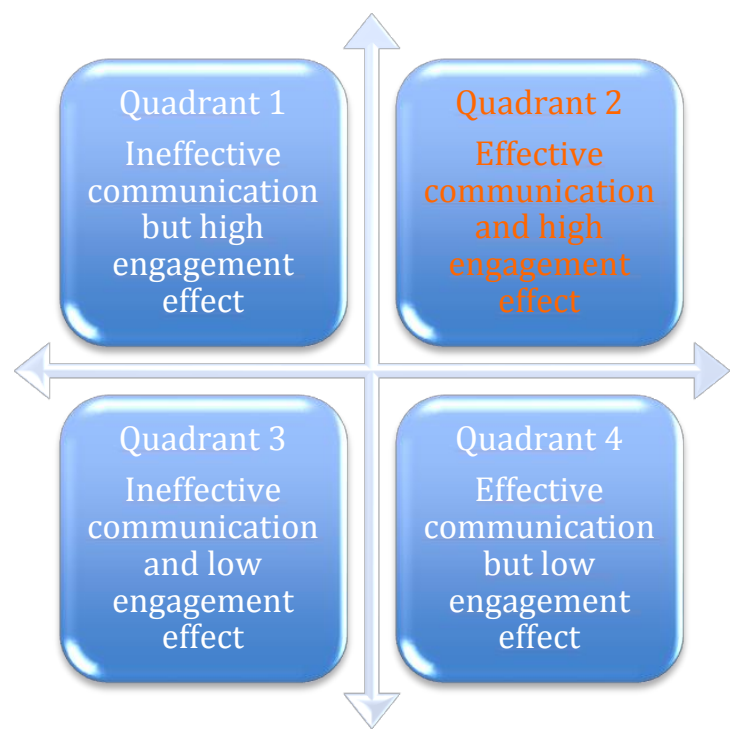

